Original

\title{
Structural Determination of Subsidiary Colors in Commercial Food Blue No.1 (Brilliant Blue FCF) Product
}

\author{
(Received September 1, 1997)
}

\author{
Hiroshi Matsufuji*1, Takashi Kusaka*1, Masatoshi Tsukuda*1, \\ Makoto Chino*1, Yoshiaki Kato*2, Mikio NAKAmurA*2, \\ Yukihiro GodA ${ }^{* 3}$, Masatake ToyodA ${ }^{* 3}$ \\ and Mitsuharu TAKEDA*1 \\ ${ }^{* 1}$ College of Bioresource Sciences, Nihon University: 3-34-1, Shimouma, Setagaya-ku, Tokyo \\ 145-0002, Japan; *2San-Ei Gen F.F.I., Inc.: 1-1-11, Sanwa-cho, Toyonaka, Osaka \\ 561-0828, Japan; ${ }^{* 3}$ National Institute of Health Sciences (NIHS): 1-18-1, \\ Kamiyoga, Setagaya-ku, Tokyo 158-8501, Japan)
}

\begin{abstract}
HPLC analysis revealed that five subsidiary colors were present in a commercial Food Blue No. 1 (Brilliant Blue FCF) product. Among them, major subsidiary colors C, D, and E were isolated. On the bases of spectroscopic analyses, their structures were identified as the disodium salt of 2-[[4-[N-ethyl- $N$-(3-sulfophenylmethyl)amino]phenyl][4-[N-ethyl- $N$-(4-sulfophenylmethyl)amino]phenyl]methylio]benzenesulfonic acid, the disodium salt of 2-[[4[ $N$-ethyl- $N$ - (2 -sulfophenylmethyl) amino] phenyl] [4-[ $N$-ethyl- $N$ - (3 -sulfophenylmethyl) amino]phenyl]methylio]benzenesulfonic acid, and the sodium salt of 2-[[4-( $N$-ethylamino)phenyl][4[ $N$-ethyl- $N$-(3-sulfophenylmethyl)amino]phenyl]methylio]benzenesulfonic acid, respectively.
\end{abstract}

Key words: Food Blue No. 1; Brilliant Blue FCF; FD \& C Blue No. 1; subsidiary color; HPLC; coal-tar dye

\section{Introduction}

Twelve coal-tar dyes are presently permitted as food colors in Japan. Several groups have reported that the commercial color products contain impurities such as raw materials, intermediates, and subsidiary colors ${ }^{1-6)}$. Recently, stricter regulations and specifications for the impurities in food colors have been called for, from the viewpoint of international harmonization. Several studies have been performed to identify and quantify subsidiary colors in Food Yellow No. $5^{31,4)}$, Food Red No. $40^{5)}$, and Food Red No. $102^{6)}$.

Food Blue No. 1 (B-1; C.I. No. 42090, Brilliant Blue FCF, FD \& C Blue No. 1, shown in Fig. 1) is classified as a triphenylmethane color prepared by condensation of 1 mole of $o$-sulfobenzaldehyde (OSBA) and 2 mole of $N$-ethyl- $N$ benzylaniline sulfonic acid (EBASA). Structur- ally, it is the disodium salt of 2 -[bis[ $44-[N$-ethyl$N$ - (3 -sulfophenylmethyl) amino] phenyl] methylio]benzensulfonic acid [OSBA- $(m-\mathrm{EBASA})(m$ EBASA)]. Stein ${ }^{7)}$ identified two subsidiary colors in commercial B-1 products by comparison of TLC data with those of synthetic compounds; one was OSBA-(ethylbenzylaniline: EBA) ( $m$ EBASA) formed by the loss of one sulfonato group from B-1, and the other was OSBA-(ethylaniline: EA)( $m$-EBASA) formed by the loss of one sulfonatobenzyl group. Furthermore, Kami$\mathrm{kura}^{2)}$ has studied their rapid determination by HPLC, and reported that OSBA-(EA) ( $m$-EBASA) content was in the range of $2.7-10.4 \%$ in ten commercial B-1 products, while OSBA-(EBA) $(m$ EBASA) was detected at a trace level in one of the products. She also suggested the existence of other unknown subsidiary colors on the basis of HPLC data, though further investigation has not yet been done. 
In this study, we examined subsidiary colors in a commercial B-1 product by HPLC analyses and investigated their chemical structures to get basic information for the regulation and specification of food colors.

\section{Materials and Methods}

\section{Materials}

A commercial B-1 product was supplied by San-Ei Gen F. F. I., Inc. Authentic B-1 for mass spectrometry (MS) and nuclear magnetic resonance (NMR) analyses was a standard product distributed by NIHS. Ammonium carbonate and methanol were purchased from Wako Chemical Co., and used without further purification. Synthetic EA-subsidiary color was kindly supplied by Dr. Kamikura.

\section{High performance liquid chromatography}

Analytical HPLC was carried out on a liquid chromatograph (Yanaco L-6000) equipped with a diode array detector (MCPD-3600, Otsuka Electronics Co., Ltd.). A $10 \mu \mathrm{L}$ aliquot of sample solution $(200 \mu \mathrm{g} / \mathrm{mL})$ was applied directly to an ODS column (4.6 mm i.d. $\times 250 \mathrm{~mm}$, Develosil UG-5, Nomura Chemical Co., Ltd.) and eluted with methanol- $0.5 \%$ ammonium carbonate $(40: 60)$ at a flow rate of $1.0 \mathrm{~mL} / \mathrm{min}$.

\section{Purification of subsidiary colors from Food Blue No.1}

Sample solution $(4 \mathrm{mg} / \mathrm{mL})$ was applied to a Develosil ODS $15 / 30$ column $(24 \mathrm{~mm}$ i.d. $\times 100$ $\mathrm{mm})$. The mobile phase of methanol- $0.5 \%$ ammonium carbonate $(38: 62)$ was used at a flow rate of $4.3 \mathrm{~mL} / \mathrm{min}$. After elution of the main peak, the mobile phase was changed to methanol-0.5\% ammonium carbonate $(45: 55)$. A 1 $\mathrm{mL}$ aliquot of the sample solution was injected for each run, and five subsidiary color fractions were collected. After several thousand runs, fractions with the same retention time were combined, dried, and rechromatographed under the same conditions described above. After the rechromatography, each subsidiary color fraction redissolved in methanol was applied to a Sephadex LH-20 column ( $20 \mathrm{~mm}$ i.d. $\times 150 \mathrm{~mm})$ to remove ammonium carbonate. Finally, about $100 \mathrm{~g}$ of commercial B-1 product afforded 1.86 $\mathrm{mg}, 3.68 \mathrm{mg}$, and $3.46 \mathrm{mg}$ of subsidiary colors $\mathrm{C}$, $\mathrm{D}$, and $\mathrm{E}$ (abbreviated as Sub-C, D, and E), respec-

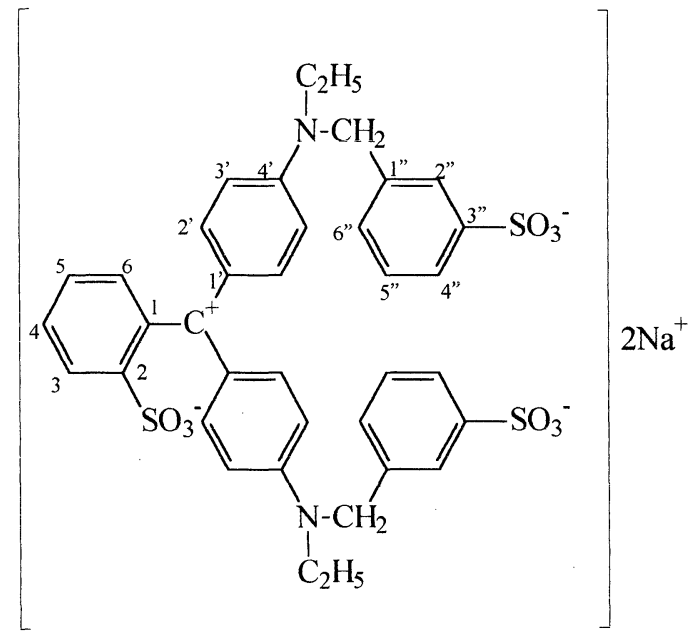

Fig. 1. Chemical structure of Food Blue No. 1 (Brilliant Blue FCF)

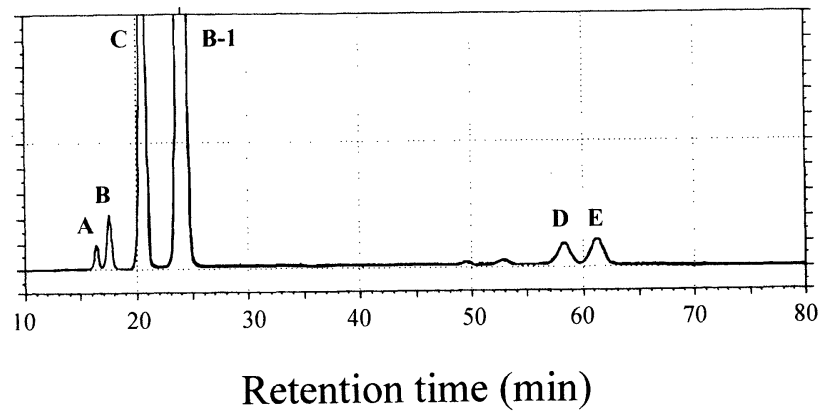

Fig. 2. HPLC profiles of commercial B-1 product at $625 \mathrm{~nm}$

Column: Develosil UG-5, eluent: $40 \% \mathrm{MeOH}$ in $0.5 \%$ ammonium carbonate, flow rate: $1.0 \mathrm{~mL} / \mathrm{min}$, temperature: $40^{\circ} \mathrm{C}$ 
Table 1. HPLC Data for Commercial B-1 Product

\begin{tabular}{lccc}
\hline \hline & Retention time $(\mathrm{min})$ & Relative peak area ${ }^{\text {a) }}(\%)$ & $\lambda_{\max }(\mathrm{nm})$ \\
\hline Sub-A & 16.4 & 0.36 & 615 \\
Sub-B & 17.6 & 1.05 & 624 \\
Sub-C & 20.6 & 18.26 & 628 \\
B-1 & 24.1 & 77.49 & 627 \\
Sub-D & 58.3 & 1.16 & 624 \\
Sub-E & 61.3 & 1.49 & 614 \\
\hline
\end{tabular}

a) Peak area was based on detection at $625 \mathrm{~nm}$.

Table 2. ${ }^{1} \mathrm{H}-\mathrm{NMR}$ Data ( $\delta$ Value, $600 \mathrm{MHz} / \mathrm{TMS}$ ) for B-1, Sub-C, Sub-D, and Sub-E in MeOH- $d_{4}{ }^{\text {a) }}$

\begin{tabular}{|c|c|c|c|c|}
\hline Position $^{\text {b) }}$ & B-1 & Sub-C & Sub-D & Sub-E \\
\hline 3 & $8.12(\mathrm{dd}, J=8.0,1.7 \mathrm{~Hz})$ & $8.11(\mathrm{~d}, J=7.8 \mathrm{~Hz})$ & $8.11(\mathrm{~d}, J=7.7 \mathrm{~Hz})$ & $8.12(\mathrm{dd}, J=7.7,1.1 \mathrm{~Hz})$ \\
\hline 4 & $7.64(\mathrm{td}, J=8.0,1.4 \mathrm{~Hz})$ & $7.64(\mathrm{t}, J=7.8 \mathrm{~Hz})$ & $7.63(\mathrm{td}, J=7.7,1.1 \mathrm{~Hz})$ & $7.63(\mathrm{td}, J=7.7,1.1 \mathrm{~Hz})$ \\
\hline 5 & $7.56(\mathrm{td}, J=8.0,1.7 \mathrm{~Hz})$ & $7.55(\mathrm{t}, J=7.8 \mathrm{~Hz})$ & $7.54(\mathrm{td}, J=7.7,1.1 \mathrm{~Hz})$ & $7.55(\mathrm{td}, J=7.7,1.1 \mathrm{~Hz})$ \\
\hline 6 & $7.09(\mathrm{dd}, J=8.0,1.4 \mathrm{~Hz})$ & $7.11(\mathrm{~d}, J=7.8 \mathrm{~Hz})$ & $7.10(\mathrm{~d}, J=7.7 \mathrm{~Hz})$ & $7.09(\mathrm{dd}, J=7.7,1.1 \mathrm{~Hz})$ \\
\hline $2^{\prime}, 6^{\prime}$ & $7.43(\mathrm{~d}, J=7.7 \mathrm{~Hz})$ & $7.42(\mathrm{br} \mathrm{d}, J=9.6 \mathrm{~Hz})$ & $7.42(\mathrm{~d}, J=8.0 \mathrm{~Hz})$ & $7.40(\mathrm{~d}, J=7.8 \mathrm{~Hz})$ \\
\hline $3^{\prime}, 5^{\prime}$ & $6.99(\mathrm{~d}, J=8.8 \mathrm{~Hz})$ & $6.99(\mathrm{~d}, J=10.2 \mathrm{~Hz})$ & $6.98(\mathrm{~d}, J=8.0 \mathrm{~Hz})$ & $6.78(\mathrm{~d}, J=9.0 \mathrm{~Hz})$ \\
\hline $2^{\prime \prime}$ & $7.74(\mathrm{~s})$ & $7.73(\mathrm{~s})$ & $7.74(\mathrm{~s})$ & $7.74(\mathrm{~s})$ \\
\hline $4^{\prime \prime}$ & $7.76(\mathrm{~d}, J=8.0 \mathrm{~Hz})$ & $7.75(\mathrm{~d}, J=7.8 \mathrm{~Hz})$ & $7.75(\mathrm{~d}, J=7.7 \mathrm{~Hz})$ & $7.75(\mathrm{~d}, J=7.7 \mathrm{~Hz})$ \\
\hline $5^{\prime \prime}$ & $7.42(\mathrm{t}, J=8.0 \mathrm{~Hz})$ & $7.42(\mathrm{br} \mathrm{t}, J=7.8 \mathrm{~Hz})$ & $7.41(\mathrm{t}, J=7.7 \mathrm{~Hz})$ & $7.42(\mathrm{t}, J=7.7 \mathrm{~Hz})$ \\
\hline $6^{\prime \prime}$ & $7.31(\mathrm{~d}, J=8.0 \mathrm{~Hz})$ & $7.32(\mathrm{~d}, J=7.8 \mathrm{~Hz})$ & $7.32(\mathrm{~d}, J=7.7 \mathrm{~Hz})$ & $7.32(\mathrm{~d}, J=7.7 \mathrm{~Hz})$ \\
\hline $2^{\prime \prime \prime}, 6^{\prime \prime \prime}$ & & $7.42(\mathrm{br} \mathrm{d}, J=9.6 \mathrm{~Hz})$ & $7.43(\mathrm{~d}, J=8.0 \mathrm{~Hz})$ & $7.37(\mathrm{~d}, J=7.8 \mathrm{~Hz})$ \\
\hline $3^{\prime \prime \prime}, 5^{\prime \prime \prime}$ & & $6.98(\mathrm{~d}, J=10.2 \mathrm{~Hz})$ & $6.98(\mathrm{~d}, J=9.3 \mathrm{~Hz})$ & $6.94(\mathrm{~d}, J=9.0 \mathrm{~Hz})$ \\
\hline $2^{\prime \prime \prime \prime}$ & & $7.31(\mathrm{~d}, J=7.8 \mathrm{~Hz})$ & & \\
\hline $3^{\prime \prime \prime \prime}$ & & $7.81(\mathrm{~d}, J=7.8 \mathrm{~Hz})$ & $8.00(\mathrm{dd}, J=7.7,1.7 \mathrm{~Hz})$ & \\
\hline $4^{\prime \prime \prime \prime}$ & & & $7.35(\mathrm{td}, J=7.7,1.7 \mathrm{~Hz})$ & \\
\hline $5^{\prime \prime \prime \prime}$ & & & $7.37(\mathrm{td}, J=7.7,1.7 \mathrm{~Hz})$ & \\
\hline $6^{\prime \prime \prime \prime}$ & & & $7.11(\mathrm{~d}, J=7.7 \mathrm{~Hz})$ & \\
\hline $\mathrm{N}-\mathrm{CH}_{2}-\underline{\mathrm{CH}_{3}}$ & $1.31(\mathrm{t}, J=7.3 \mathrm{~Hz})$ & $1.31(\mathrm{t}, J=7.1 \mathrm{~Hz})$ & $1.30(\mathrm{t}, J=6.9 \mathrm{~Hz})$ & $1.31(\mathrm{t}, J=7.2 \mathrm{~Hz})$ \\
\hline$N-\underline{\mathrm{CH}_{2}}-\overline{\mathrm{CH}_{3}}$ & $3.77(\mathrm{q}, J=7.3 \mathrm{~Hz})$ & $3.78(\mathrm{~m})$ & $3.76(\mathrm{~m})$ & $3.74(\mathrm{q}, J=7.2 \mathrm{~Hz})$ \\
\hline$N-\overline{\mathrm{CH}_{2}}-\mathrm{Ar}$ & $4.93(\mathrm{~s})$ & $4.93(\mathrm{~s})$ & $4.98(\mathrm{~s})$ & $4.90(\mathrm{~s})$ \\
\hline$N^{\prime}-\mathrm{CH}_{2}^{\prime}-\mathrm{CH}_{3}^{\prime}$ & & $1.29(\mathrm{t}, J=5.4 \mathrm{~Hz})$ & $1.36(\mathrm{t}, J=6.9 \mathrm{~Hz})$ & $1.29(\mathrm{t}, J=7.2 \mathrm{~Hz})$ \\
\hline$N^{\prime}-\mathrm{CH}_{2}^{\prime}-\overline{\mathrm{CH}_{3}^{\prime}}$ & & $3.63(\mathrm{~m})$ & $3.78(\mathrm{~m})$ & $3.44(\mathrm{q}, J=7.2 \mathrm{~Hz})$ \\
\hline$N^{\prime} \cdot \overline{\mathrm{CH}_{2}^{\prime}}-\mathrm{Ar}$ & & $4.87(\mathrm{~s})$ & 5.36 and 5.37 (each s) & \\
\hline
\end{tabular}

a) Multiplicities and coupling constants are given in parentheses.

b) Position on the ethylaniline moiety is indicated by prime and triple prime, and position on the sulfonatobenzene moiety by double prime and quartet prime, respectively.

tively.

\section{Spectroscopic analyses}

MS analyses were done under the following conditions: negative-mode electrospray ionization, a scan speed of $100-1,000 \mathrm{~m} / z$ for $3 \mathrm{sec}$, and a cone voltage of $30 \mathrm{~V}$. Each sample was dissolved in water and directly injected.

${ }^{1} \mathrm{H}-(600 \mathrm{MHz})$ and ${ }^{13} \mathrm{C}-\mathrm{NMR}(150 \mathrm{MHz})$ spectra were measured on a JEOL A600 spectrophotometer in methanol- $d_{4}$ with tetramethylsilane as the internal standard. The signals of the ${ }^{1} \mathrm{H}$ - and
${ }^{13} \mathrm{C}-\mathrm{NMR}$ spectra of $\mathrm{B}-1$ and subsidiary colors were assigned on the bases of chemical shifts and the results of correlation spectroscopy (COSY), heteronuclear multiple quantum coherence (HMQC), and heteronuclear multiple bond connectivity (HMBC) studies.

\section{Results}

\section{Subsidiary colors in commercial $B-1$ product}

To clarify the presence of subsidiary colors in commercial B-1 products, analytical HPLC with a diode array detector was performed. A 
Table 3. ${ }^{13} \mathrm{C}-\mathrm{NMR}$ Chemical Shifts $(\delta$ Value, $150 \mathrm{MHz} / \mathrm{TMS}$ ) of B-1, Sub-C, Sub-D and Sub-E in $\mathrm{MeOH}-d_{4}$

\begin{tabular}{|c|c|c|c|c|}
\hline Position $^{\text {a) }}$ & B-1 & Sub-C & Sub-D & Sub-E \\
\hline 1 & 138.3 & 138.4 & 138.4 & 138.5 \\
\hline 2 & 146.3 & 146.4 & 146.5 & 146.5 \\
\hline 3 & 129.3 & 129.4 & 129.5 & 129.4 \\
\hline 4 & 131.3 & 131.3 & 131.3 & 131.2 \\
\hline 5 & 130.7 & 130.8 & 130.7 & 130.7 \\
\hline 6 & 132.8 & 132.8 & 132.8 & 132.8 \\
\hline $1^{\prime}$ & 129.2 & 129.3 & 129.3 & 129.5 \\
\hline $2^{\prime}, 6^{\prime}$ & 142.2 & 142.3 & 142.2 & 141.3 \\
\hline $3^{\prime}, 5^{\prime}$ & 114.9 & 114.9 & 114.8 & 114.3 \\
\hline $4^{\prime}$ & 157.8 & 157.8 & 157.8 & 156.8 \\
\hline $1^{\prime \prime}$ & 138.1 & 138.2 & 138.3 & 138.6 \\
\hline $2^{\prime \prime}$ & 125.3 & 125.3 & 125.4 & 125.3 \\
\hline $3^{\prime \prime}$ & 147.0 & 147.2 & 147.2 & 147.2 \\
\hline $4^{\prime \prime}$ & 126.3 & 126.4 & 126.4 & 126.3 \\
\hline $5^{\prime \prime}$ & 130.1 & 130.1 & 130.1 & 130.0 \\
\hline $6^{\prime \prime}$ & 129.5 & 129.5 & 129.4 & 129.5 \\
\hline $1^{\prime \prime \prime}$ & & 129.3 & 129.3 & 128.9 \\
\hline $2^{\prime \prime \prime}, 6^{\prime \prime \prime}$ & & 142.2 & 142.3 & 141.3 \\
\hline $3^{\prime \prime \prime}, 5^{\prime \prime \prime}$ & & 114.9 & 115.0 & 114.3 \\
\hline $4^{\prime \prime \prime}$ & & 157.9 & 158.3 & 160.0 \\
\hline $1^{\prime \prime \prime \prime}$ & & 140.1 & 135.0 & \\
\hline $2^{\prime \prime \prime \prime}$ & & $127.7^{\mathrm{b})}$ & 144.2 & \\
\hline $3^{\prime \prime \prime \prime}$ & & $126.6^{\mathrm{b})}$ & 128.8 & \\
\hline $4^{\prime \prime \prime \prime}$ & & 145.9 & 128.3 & \\
\hline $5^{\prime \prime \prime \prime}$ & & & 131.8 & \\
\hline $6^{\prime \prime \prime \prime}$ & & & 127.2 & \\
\hline$N-\mathrm{CH}_{2}-\mathrm{CH}_{3}$ & 12.8 & 12.8 & 12.7 & 12.7 \\
\hline $\mathrm{N}-\mathrm{CH}_{2}-\mathrm{CH}_{3}$ & 47.8 & $47.9^{c)}$ & 47.7 & 47.5 \\
\hline$N-\mathrm{CH}_{2}-\mathrm{Ar}$ & 54.8 & 54.8 & 54.8 & 54.7 \\
\hline$N^{\prime}-\mathrm{CH}_{2}^{\prime}-\mathrm{CH}_{3}^{\prime}$ & & 12.8 & 12.9 & 14.3 \\
\hline$N^{\prime}-\mathrm{CH}_{2}^{\prime}-\mathrm{CH}_{3}^{\prime}$ & & $47.8^{c)}$ & 48.1 & 39.3 \\
\hline$N^{\prime}-\overline{\mathrm{CH}_{2}^{\prime}}-\mathrm{Ar}$ & & 54.7 & 53.1 & \\
\hline $\mathrm{C}^{+}$ & 178.9 & 179.0 & 179.0 & 178.2 \\
\hline
\end{tabular}

a) Position on the ethylaniline moiety is indicated by prime and triple prime, and position on the sulfonatobenzene moiety by double prime and quartet prime, respectively.

b,c) Signal may be interchanged within each column.

chromatogram of commercial B-1 product at 625 $\mathrm{nm}$ is shown in Fig. 2. Five peaks having relative peak areas equal to $0.36 \%$ or larger (Table 1) were observed besides the peak of $B-1$, and were named Sub-A, B, C, D, and E. Of these unidentified subsidiary colors, Sub-C, Sub-D, and Sub$\mathrm{E}$ were major in the commercial B-1 product. Therefore, the chromatographic purification of these subsidiary colors was conducted.
The absorption maxima for Sub-C and Sub-D were 628 and $624 \mathrm{~nm}$, respectively, and they were similar to that of B-1. This finding implies that the structures of these subsidiary colors might be analogous to that of B-1. On the other hand, the hypsochromic shift in Sub-E suggests shortening of the conjugated system, such as elimination of an aromatic ring.

\section{Spectroscopic analyses of subsidiary colors}

In the mass spectra of Sub-C and Sub-D, a quasi-molecular ion peak at $m / z 373[\mathrm{M}-$ $2 \mathrm{Na}]^{2-} / 2$ was observed as well as that of B-1. The ion peak indicates that the molecular formulae of Sub-C and Sub-D can be represented as $\mathrm{C}_{37} \mathrm{H}_{34} \mathrm{~N}_{2} \mathrm{Na}_{2} \mathrm{O}_{9} \mathrm{~S}_{3}$, and that these compounds are isomers of B-1. For Sub-E, a quasi-molecular ion peak at $m / z 577[\mathrm{M}-\mathrm{Na}]^{-}$was observed, implying the molecular formula $\mathrm{C}_{30} \mathrm{H}_{29} \mathrm{~N}_{2} \mathrm{NaO}_{6} \mathrm{~S}_{2}$.

The ${ }^{1} \mathrm{H}$ - and ${ }^{13} \mathrm{C}-\mathrm{NMR}$ data for Sub-C, Sub-D, Sub-E, and B-1 are summarized in Tables 2 and 3 , respectively. The ${ }^{1} \mathrm{H}-$ and ${ }^{13} \mathrm{C}-\mathrm{NMR}$ data for Sub-C and Sub-D were similar to those of B-1 except for the signals derived from one sulfonatophenyl moiety. Namely, in the spectrum of Sub-C, a pair of doublet proton signals at $\delta 7.31$ (assigned to the $3^{\prime \prime \prime \prime}$ - and $5^{\prime \prime \prime \prime}$-positions) and $\delta 7.81$ (assigned to the $2^{\prime \prime \prime \prime}$ - and $6^{\prime \prime \prime \prime}$ positions) and four carbon signals at $\delta 140.1$ (assigned to the $1^{\prime \prime \prime \prime}$-position), $\delta 127.7$ (assigned to the $2^{\prime \prime \prime \prime}$ - and $6^{\prime \prime \prime \prime}$-positions), $\delta 127.6$ (assigned to the $3^{\prime \prime \prime \prime}$ - and $5^{\prime \prime \prime \prime}$-positions), and $\delta 145.9$ (assigned to the $4^{\prime \prime \prime \prime}$-position) were observed for the sulfonatophenyl moiety. This clearly indicates that the sulfonato group is located at the $4^{\prime \prime \prime \prime}$-position. Thus, Sub-C was concluded to be the disodium salt of $2-[[4-[N$-ethyl- $N-(3-$ sulfophenylmethyl)amino]phenyl][4-[ $N$-ethyl- $N$ (4-sulfophenylmethyl) amino] phenyl] methylio]benzenesulfonic acid [abbreviated as OSBA- $(p$ EBASA) ( $m$-EBASA)], as shown in Fig. 3 . On the other hand, in the proton spectrum of Sub-D, two double-triplet signals at $\delta 7.35$ (assigned to the $4^{\prime \prime \prime \prime}$-position) and $\delta 7.37$ (assigned to the $5^{\prime \prime \prime \prime}$ position), a double-doublet signal at $\delta 8.00$ (assigned to the $3^{\prime \prime \prime \prime}$-position), and a doublet signal at $\delta 7.11$ (assigned to the $6^{\prime \prime \prime \prime}$-position) were observed for the sulfonatophenyl moiety. These data indicate that the substituents are located at the $1^{\prime \prime \prime \prime}$ - and $2^{\prime \prime \prime \prime}$-positions. The HMBC analy- 


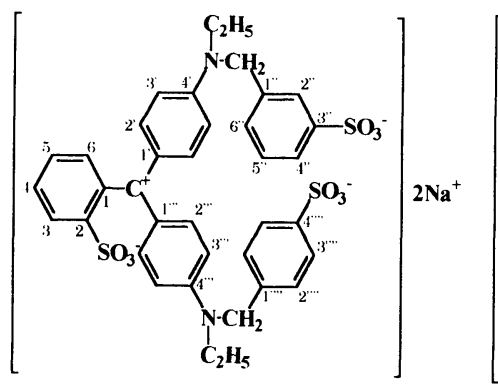

Sub-C

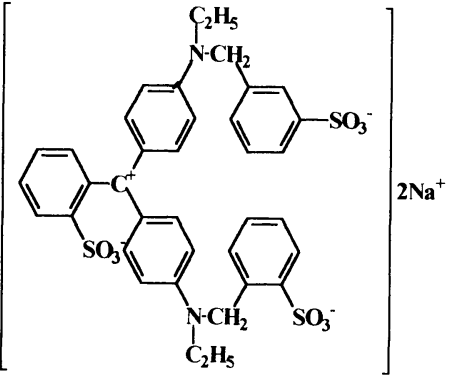

Sub-D

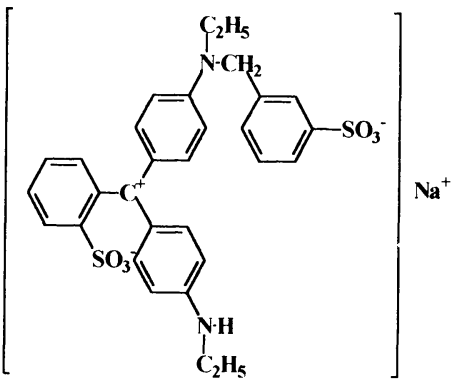

Sub-E

Fig. 3. Chemical structures of Sub-C, Sub-D, and Sub-E

ses also support this idea. In the HMBC spectrum, the methylene proton signals (at $\delta 5.36$ and $\delta 5.37, N^{\prime}-\mathrm{CH}_{2}{ }^{\prime}$-Ar), double-triplet proton signal at $\delta 7.35$ (assigned to the $4^{\prime \prime \prime \prime}$-position), and doublet proton signal at $\delta 7.11$ (assigned to the $6^{\prime \prime \prime \prime}$. position) were correlated to the quaternary carbon signal at $\delta 144.2$ (assigned to the $2^{\prime \prime \prime \prime}$. position). This clearly indicates that the sulfonato group is located at the $2^{\prime \prime \prime \prime}$-position. On the bases of these data, Sub-D was concluded to be the disodium salt of 2-[[4-[N-ethyl- $N-(2-$ sulfophenylmethyl)amino $]$ phenyl $][4-[N$-ethyl- $N$ (3-sulfophenylmethyl)amino]phenyl]methylio]benzenesulfonic acid (Fig. 3; abbreviated as OSBA-(o-EBASA) ( $m$-EBASA)).

The ${ }^{1} \mathrm{H}$ - and ${ }^{13} \mathrm{C}-\mathrm{NMR}$ data for Sub-E and the result of MS analysis imply that Sub-E lacks one sulfonatobenzyl group from B-1. Namely, in the ${ }^{1} \mathrm{H}$ - and ${ }^{13} \mathrm{C}-\mathrm{NMR}$ spectra, the signal intensity in one EBASA moiety was reduced to one-half that of B-1 and two doublet proton signals at $\delta 7.37$ (assigned to the $2^{\prime \prime \prime}$ - and $6^{\prime \prime \prime}$-positions) and $\delta$ 6.94 (assigned to the $3^{\prime \prime \prime}$ - and $5^{\prime \prime \prime}$-positions) due to the ethylaniline moiety were observed. In addition, in the HMBC spectrum, the proton signal at $\delta 7.37$ and the doublet proton signal at $\delta 7.40$ (assigned to the $2^{\prime}$ - and $66^{\prime}$-positions) were correlated to the carbon signal at $\delta 178.2$ (assigned to the center carbon). Also, the methylene proton signal at $\delta 3.44$ (assigned to $N^{\prime}-\mathrm{CH}_{2}{ }^{\prime}-\mathrm{CH}_{3}{ }^{\prime}$ ) showed the correlation to the carbon signals at $\delta 14.3$ (assigned to $N^{\prime}-\mathrm{CH}_{2}{ }^{\prime}-\mathrm{CH}_{3}{ }^{\prime}$ ) and $\delta 160.0$ (assigned to the $4^{\prime \prime \prime}$-position). Therefore, Sub-E was concluded to be the sodium salt of 2 [[4-( $N$-ethylamino) phenyl][4-[ $N$-ethyl- $N$-(3-sulfophenylmethyl)amino]phenyl]methylio]benzene- sulfonic acid (Fig. 3). This is the same compound, OSBA-(EA) ( $m$-EBASA), that Stein ${ }^{7)}$ and Kamikura $^{2)}$ reported as an EA-subsidiary color. Co-injection analysis of Sub-E and synthetic EA-subsidiary color in HPLC confirmed the structure.

\section{Discussion}

Several investigators ${ }^{7-9)}$ have suggested that five isomers of B-1, OSBA-( $p$-EBASA) $(m$ EBASA), OSBA-( $o$-EBASA) $(m$-EBASA), OSBA$(p$-EBASA $), \quad(p$-EBASA), OSBA- $(o$-EBASA) $(p$ EBASA), and OSBA-(o-EBASA) (o-EBASA) are likely to be present in commercial B-1 products because EBASA, the starting material, consists of a mixture of isomers, about $80 \% \mathrm{~m}$-EBASA, 15-20\% $p$-EBASA, and 0-5\% $o$-EBASA. However, no data are available regarding their separation by modern chromatographic techniques or spectroscopic identifications. Under our HPLC conditions, three isomers (OSBA- $(p$-EBASA) $(m$ EBASA), B-1, and OSBA-( $o$-EBASA) ( $m$-EBASA)) could be clearly separated. Their peak area ratios at $625 \mathrm{~nm}$ in the commercial B-1 product used in this study were $18.7,78.1$, and $1.2 \%$, respectively. The good agreement between the peak area ratio of the three isomers and the mixture ratio of EBASA indicates that these subsidiary colors were derived from impurities of the starting material. An unidentified subsidiary color, OSBA-( $p$-EBASA) ( $p$-EBASA) should be eluted before Sub-C, considering the polarity resulting from the location of the sulfonato group; therefore, of the remaining peaks, peak A or B may correspond to this compound.

We are continuing to investigate the struc- 
tures and quantitative determination of the other subsidiary colors (Sub-A and B).

\section{Acknowledgment}

We are grateful to Dr. Kamikura for providing synthetic EA-subsidiary color.

\section{References}

1) Kamikura, M.: J. Food Hyg. Soc. Japan 27, 398407 (1986).

2) Kamikura, M.: ibid. 27, 27-36 (1986).

3) Yamada, M., Nakamura, M., Yamada, T., Maitani, T., Goda, Y.: Jpn. J. Food Chem. 3, 151-155 (1996).
4) Yamada, M., Nakamura, M., Yamada, T., Maitani, T., Goda, Y.: Chem. Pharm. Bull. 44, 1,6241,627 (1996).

5) Takeda, Y., Goda, Y., Noguchi, H., Yamada, T., Yoshihira, K., Takeda, M.: Food Additives and Contaminants 11, 97-104 (1994).

6) Yamada, M., Kato, Y., Nakamura, M., Ishimitsu, S., Shibata, T., Ito Y.: J. Food Hyg. Soc. Japan 36, 417-422 (1995).

7) Stein, C.: J. Assoc. Off. Anal. Chem. 52, 34-40 (1969).

8) Jones, J. H., Dolinsky, M., Harrow, L. S., Heine, K. S., Staves, M. C.: ibid. 38, 977-1,010 (1955).

9) Wilson, C. H., Dolinsky, M.: ibid. 47, 1,153-1,157 (1964). 